University of Nebraska - Lincoln

DigitalCommons@University of Nebraska - Lincoln

USDA National Wildlife Research Center - Staff Publications
U.S. Department of Agriculture: Animal and Plant Health Inspection Service

2012

\title{
Mucosal Adjuvants to Improve Wildlife Rabies Vaccination
}

Tricia Fry

US Department of Agriculture, tricia.I.fry@aphis.usda.gov

Kaci K. VanDalen

USDA/APHIS/WS National Wildlife Research Center, kaci.vandalen@aphis.usda.gov

Jerome Hurley

US Department of Agriculture

Paul Nash

US Department of Agriculture

Follow this and additional works at: https://digitalcommons.unl.edu/icwdm_usdanwrc

Fry, Tricia; VanDalen, Kaci K.; Hurley, Jerome; and Nash, Paul, "Mucosal Adjuvants to Improve Wildlife Rabies Vaccination" (2012). USDA National Wildlife Research Center - Staff Publications. 1137.

https://digitalcommons.unl.edu/icwdm_usdanwrc/1137

This Article is brought to you for free and open access by the U.S. Department of Agriculture: Animal and Plant Health Inspection Service at DigitalCommons@University of Nebraska - Lincoln. It has been accepted for inclusion in USDA National Wildlife Research Center - Staff Publications by an authorized administrator of DigitalCommons@University of Nebraska - Lincoln. 


\section{Mucosal Adjuvants to Improve Wildlife Rabies Vaccination}

Tricia Fry, ${ }^{1,3}$ Kaci Van Dalen, ${ }^{1}$ Jerome Hurley, ${ }^{1}$ and Paul Nash ${ }^{1,2}{ }^{1}$ US Department of Agriculture, Animal and Plant Health Inspection Service, Wildlife Services, National Wildlife Research Center, 4101 Laporte Ave., Fort Collins, Colorado 80521, USA; ${ }^{2}$ Department of Biology, University of West Florida, 11000 University Pkwy., Pensacola, Florida 32514, USA; ${ }^{3}$ Corresponding author (email: tricia.l.fry@ aphis.usda.gov)

ABSTRACT: RABORAL V-RG ${ }^{\circledR a}$ is a recombinant vaccine used in oral rabies vaccination (ORV) programs for wildlife in the United States. Vaccination rates for raccoons are substantially lower than vaccination rates for gray foxes and coyotes. Research suggests that the low viscosity of the oral vaccine may preclude animals from receiving an effective dose when biting into the vaccine bait delivery system. We evaluated the possibility of using two benign compounds, chitosan and N,N,Ntrimethylated chitosan (TMC), to increase the viscosity of the vaccine and potentially act as adjuvants to improve the immune response in raccoons (Procyon lotor). Forty mildly sedated raccoons were orally vaccinated via needleless syringe with either RABORAL V-RG $(n=12)$, chitosan+RABORAL V-RG $(n=12), \quad$ TMC+ RABORAL V-RG $(n=12)$, or no vaccine $(n=4)$, on day 0 and again on day 90 . We collected sera every $2-4 \mathrm{wk}$ for $4 \mathrm{mo}$ and evaluated rabies virus-neutralizing antibodies (rVNA). Raccoons were considered responders if $\mathrm{rVNA}$ titers were $\geq 0.1 \mathrm{IU} / \mathrm{mL}$. Eleven of 12 raccoons vaccinated with TMC+RABORAL $\mathrm{V}-\mathrm{RG}$ responded after one dose of vaccine, as did eight of 12 vaccinated with RABORAL VRG, and three of 12 vaccinated with chitosan+ RABORAL V-RG. Our results suggest that the inclusion of an adjuvant, such as TMC, could increase vaccine efficacy to aid in controlling rabies virus spread in wildlife reservoirs.

Key words: Adjuvant, chitosan, oral vaccination, rabies, raccoon, vaccine.

In North America, rabies is maintained by wildlife reservoirs. To reduce the prevalence of rabies in wild carnivores, RABORAL V-RG ${ }^{\circledR}$ (Merial Ltd., Athens, Georgia, USA) oral rabies vaccines (ORV) are distributed in the United States east of the Appalachian Mountains, as well as portions of Ohio, Arizona, New Mexico, and Texas. Vaccination rates in Texas have been sufficiently high to control rabies in

\footnotetext{
${ }^{\mathrm{a}}$ RABORAL V-RG ${ }^{\circledR}$ is a registered trademark of Merial Ltd. (Athens, Georgia, USA). All other marks are the property of their respective owners.
}

gray fox (Urocyon cinereoargenteus) and coyotes (Canis latrans; Fearneyhough et al., 1998; Sidwa et al., 2005). Eisinger and Thulke (2008) suggest that a vaccination rate of $60 \%$ is sufficient to break the pathogen transmission cycle; however, the ORV program in the United States successfully vaccinates only about $30 \%$ of raccoons (Procyon lotor) (Slate et al., 2009).

The RABORAL V-RG vaccine is delivered as a liquid contained within a plastic sachet coated with fish meal or a sachet surrounded within a fish-meal polymer. Under optimal conditions, when the sachet is pierced by an animal, the vaccine is released into the mouth, coating the mucosae. The recombinant vaccine attaches and enters host cells and expresses the rabies virus glycoprotein, triggering an immune response. It is unknown why vaccination rates in raccoons are lower than gray foxes and coyotes. One reason could be that the vaccine is not as immunogenic in raccoons, suggesting the need for an adjuvant. Another reason could be vaccine spillage, suggesting the need for a more viscous vaccine mixture. While foxes and coyotes tend to pick up the entire bait with their mouth, releasing a full dose of vaccine into the buccal cavity as they chew, raccoons hold the vaccine sachet on the ground and bite only small portions at a time, allowing the open sachet to leak. Pen trials have repeatedly shown raccoons spilling much of the liquid contents of the sachet (Brown et al., 2011).

We investigated two compounds with adjuvant properties that also increase vaccine viscosity: chitosan and $\mathrm{N}, \mathrm{N}, \mathrm{N}-$ trimethylated chitosan (TMC). Chitin is a nontoxic polymer that naturally occurs in crustaceans, insects, and mushrooms. 
When chitin is deacetylated, it becomes chitosan, a safe, natural cationic polysaccharide that is highly biodegradable, has a relatively neutral $\mathrm{pH}$ when combined with a phosphate buffer solution, and has low toxicity (Dodane et al., 1999). When neutralized, chitosan forms a gelatinous precipitate, which increases the bioavailability of vaccines or drugs (Baudner et al., 2004) and enhances transport and absorption across the epithelial barrier by disrupting tight junctions in the mucosa and activating macrophages and cytotoxic T-lymphocytes (van der Lubben et al., 2001). The compound TMC is a chitosan derivative that exhibits similar utility as a thickener and adjuvant (LueBen et al., 1996). TMC is more soluble at neutral $\mathrm{pH}$ than chitosan, but it maintains the immunogenic and adhesive properties of chitosan (Kotze et al., 1997).

TMC was produced from commercially available chitosan (Sigma-Aldrich, St. Louis, Missouri, USA). Multiple additions of methyl iodine were made into a suspension of finely ground chitosan in Nmethylpyrrolidone, and sodium hydroxide $(\mathrm{NaOH})$ was added to neutralize the hydroiodic acid by-product. When the reaction was completed, the mixture was dialyzed against multiple changes of sodium chloride $(\mathrm{NaCl})$ solutions. The resulting dialysis product was freeze-dried to yield TMC powder. TMC was made into a stock solution concentration of $5 \%$ in Roswell Park Memorial Institute media (RPMI; Sigma-Aldrich), while the limited solubility of chitosan dictated a $1 \%$ chitosan stock solution. Both solutions were sterilized by autoclaving prior to mixing with RABORAL V-RG. Our objective was to determine if the addition of either chitosan or TMC affected the humoral immune response of raccoons to RABORAL V-RG.

Forty raccoons were trapped using appropriate-sized TOMAHAWK Live Traps ${ }^{\circledR}$ (Hazelhurst, Wisconsin, USA) in Larimer County, Colorado $\left(40^{\circ} 35.403^{\prime} \mathrm{N}\right.$, $\left.105^{\circ} 9.146^{\prime} \mathrm{W}\right)$. Raccoons were housed individually in $3 \times 3 \times 2.5-\mathrm{m}$ pens that included den boxes and enrichment structures at the US Department of Agriculture National Wildlife Research Center's Outdoor Animal Research Facility (Fort Collins, Colorado, USA) for the duration of the study. Prior to the experiment, raccoons were evaluated for health after intramuscular administration with $10 \mathrm{mg} /$ $\mathrm{kg}$ ketamine $\mathrm{HCl}$ and $2 \mathrm{mg} / \mathrm{kg}$ xylazine (Deresienski and Rupprecht, 1989). Ivo$\mathrm{mec}^{\circledR}(0.1 \mathrm{~mL} / 5 \mathrm{~kg}$, per os, Merial) was also administered to raccoons to control internal parasites, and raccoons were vaccinated for distemper with the GALAXY D ${ }^{\circledR}$ vaccine (Schering-Plough Animal Health Corporation, Boxmeer, The Netherlands) and microchipped (Avid Identification Systems, Inc., Norco, California, USA). Blood was collected via venipuncture of the jugular vein to measure baseline rabies virus-neutralizing antibody (rVNA) titers. Raccoons were quarantined for a minimum of 14 days. The Institutional Animal Care and Use Committee at the National Wildlife Research Center approved all experimental procedures and animal holding conditions.

Prior to the experiment, the RABORAL V-RG vaccine titer was determined to be $10^{7.4} 50 \%$ Tissue culture infectious dose $\left(\right.$ TCID $\left._{50}\right) / \mathrm{mL}$. Three vaccine formulations were prepared in 2-mL dosages: $2 \mathrm{~mL}$ of RABORAL V-RG alone $\left(10^{7.7}\right.$ TCID $\left._{50}\right)$, $1 \mathrm{~mL}$ of RABORAL V-RG+1 $\mathrm{mL}$ of $1 \%$ chitosan (10 ${ }^{7.4}$ TCID $_{50}$ ), and $1 \mathrm{~mL}$ of RABORAL V-RG+1 $\mathrm{mL}$ of $5 \%$ TMC $\left(10^{7.4}\right.$ TCID $\left._{50}\right)$. Antibody-negative raccoons were randomly placed into one of four groups: chitosan+RABORAL V-RG $(n=12)$, TMC+RABORAL V-RG $(n=12)$, RABORAL V-RG only $(n=12)$, or no vaccine $(n=4)$. After sedation with 10 $\mathrm{mg} / \mathrm{kg}$ ketamine $\mathrm{HCl}$ and $2 \mathrm{mg} / \mathrm{kg}$ xylazine, blood was collected from each raccoon, and $2-\mathrm{mL}$ aliquots of the vaccine mixture were delivered via needleless syringe into the mouth. Raccoons swallowed the mixture, and the volume of the vaccine consumed was confirmed. The day of vaccination was considered 0 days postinoculation (dpi). 
TABLE 1. Summary of rabies virus-neutralizing antibodies (IU/mL) in raccoons (Procyon lotor) vaccinated with RABORAL V-RG, trimethylated chitosan combined with RABORAL V-RG (TMC+RABORAL V-RG), chitosan combined with RABORAL V-RG (chitosan+RABORAL V-RG), or nonvaccinated control raccoons from day 0 to day 126 postvaccination.

\begin{tabular}{ccccl}
\hline Days postvaccination & RABORAL V-RG & TMC+RABORAL V-RG & Chitosan+RABORAL V-RG & No vaccine \\
\hline 0 & $0.04^{\mathrm{a}}(12)^{\mathrm{b}}$ & $0.04(12)$ & $0.04(12)$ & $0.04(4)$ \\
& $0.04-0.04^{\mathrm{c}}$ & $0.04-0.04$ & $0.04-0.04$ & $0.04-0.04$ \\
7 & $0.056(12)$ & $0.04(12)$ & $0.04(12)$ & $0.04(4)$ \\
& $0.04-0.104$ & $0.04-0.04$ & $0.04-0.04$ & $0.04-0.04$ \\
14 & $0.202(12)$ & $0.192(12)$ & $0.069(12)$ & $0.04(4)$ \\
& $0.04-0.448$ & $0.04-0.448$ & $0.04-0.336$ & $0.04-0.040$ \\
21 & $0.188(12)$ & $0.334(12)$ & $0.093(12)$ & $0.04(4)$ \\
& $0.04-0.4$ & $0.04-0.488$ & $0.04-0.40$ & $0.04-0.04$ \\
28 & $0.232(12)$ & $0.307(12)$ & $0.126(12)$ & $0.073(4)$ \\
& $0.04-0.488$ & $0.04-0.448$ & $0.04-0.48$ & $0.05-0.08$ \\
60 & $0.456(12)$ & $0.582(12)$ & $0.155(12)$ & $0.05(4)$ \\
& $0.05-0.62$ & $0.05-0.89$ & $0.05-0.620$ & $0.05-0.05$ \\
90 & $0.32(11)$ & $0.484(12)$ & $0.168(11)$ & $0.08(4)$ \\
& $0.05-0.62$ & $0.05-0.62$ & $0.05-0.62$ & $0.08-0.08$ \\
104 & $0.792(11)$ & $0.838(12)$ & $0.391(11)$ & $0.08(4)$ \\
& $0.16-0.89$ & $0.60-0.89$ & $0.08-0.89$ & $0.08-0.08$ \\
126 & $0.758(11)$ & $0.811(12)$ & $0.457(11)$ & $0.08(4)$ \\
& $0.18-0.89$ & $0.180-0.890$ & $0.08-0.89$ & $0.08-0.08$ \\
\hline
\end{tabular}

a Mean (IU/mL).

${ }^{\mathrm{b}}$ Sample size $(n)$.

${ }^{\mathrm{c}}$ rVNA range $(\mathrm{IU} / \mathrm{mL})$.

On 90 dpi, all raccoons received a 2-mL booster dose of the vaccine formulation or placebo vaccine (two raccoons were euthanized for health reasons unrelated to the study before $90 \mathrm{dpi}$ ). To follow rVNA development, animals were anesthetized and blood was collected at 4, 14, 21, 28, 60, 90, 104, and 126 dpi. Rabies VNA titers were measured at the Centers for Disease Control and Prevention, Atlanta, Georgia, USA, using the rapid fluorescent focus inhibition test (RFFIT), as described by Smith et al. (1996).

We considered raccoons with rVNA titers $\geq 0.1 \mathrm{IU} / \mathrm{mL}$ to be responders. Table 1 summarizes the mean and range of rVNA titers over the course of the study. The chitosan+RABORAL V-RG vaccine was consistently less effective at eliciting a humoral immune response than either the RABORAL V-RG vaccine or the TMC+RABORAL V-RG vaccine (Table 2). Before the 90 dpi booster, 11 of 12 raccoons vaccinated with TMC+RABORAL V-RG responded with $\mathrm{rVNA} \geq 0.1 \mathrm{IU} / \mathrm{mL}$, as compared with eight of 12 raccoons vaccinated with RABOARL V-RG alone. Logistic regression suggested that vaccination with TMC+RABORAL V-RG $(P<0.01)$ and RABOARL V-RG $(P<0.05)$ resulted in a greater number of responders than the chitosan+RABORAL V-RG treatment group prior to the boost vaccination at day 90. Using the Wald test to compare factors within the logistic regressions, there was not a significant difference between TMC+RABORAL V-RG and RABOARL V-RG $(P=0.16)$. After the vaccine booster, logistic regression demonstrated there was no difference between vaccine formulations $(P=0.997)$. However, rabies VNA titers among the three vaccine combinations were significantly different $\left(F_{3,32}=9.07, P<0.001\right)$, with raccoons receiving TMC+RABORAL V-RG producing higher rVNA titers.

Exploration into mucosal adjuvants provides at least two potential avenues to 
TABLE 2. Summary of the number of individual raccoons (Procyon lotor) responding to RABORAL V-RG ${ }^{\circledR}$ vaccine formulations.

\begin{tabular}{lcc}
\hline \multicolumn{1}{c}{ Treatment } & $\begin{array}{c}\text { No. raccoons with rabies VNA } \geq 0.1 \mathrm{IU} / \mathrm{mL} \\
\text { prior to boost at } 90 \text { days }(n)\end{array}$ & $\begin{array}{c}\text { No. raccoons with rabies VNA } \\
\text { RABORAL V-RG }\end{array}$ \\
\hline Chitosan+RABORAL V-RG & $8(12)$ & $11(11)$ \\
TMC+RABORAL V-RG & $3(12)$ & $7(11)$ \\
No vaccine & $11(12)$ & $12(12)$ \\
& $0(4)$ & $0(4)$ \\
\hline
\end{tabular}

increase effectiveness of this vaccine in raccoons: 1) increasing the host's immunologic response to the vaccination and 2) increasing vaccine viscosity. Chitosan and its derivatives have been used as adjuvants in drug-delivery systems; however, we are the first to test these mucosal adjuvants with the RABORAL V-RG rabies vaccine. After a dose of chitosan+RABORAL VRG, only three of 12 individuals produced rVNA, and after a booster vaccination with the same mixture, only seven of 11 raccoons had detectable rVNA. One possible explanation for the lack of responders in the chitosan+RABORAL V-RG treatment group may be related to the physical and chemical properties of chitosan upon vaccine administration. First, unlike TMC, chitosan is not water soluble, which may decrease its utility in the oral cavity particularly when the vaccine is administered by direct instillation, as we did in this study. Consequently, the chitosanvaccine mixture may not be sustained in the oral cavity long enough to allow adequate vaccine uptake. Secondly, vaccine uptake could also have been compromised if chitosan encapsulated the vaccine, thus limiting the availability of RABORAL V-RG.

While one dose of the current RABORAL V-RG formulation was enough to produce rVNA in eight of 12 individuals, only after a booster vaccination did $100 \%$ of raccoons exhibit rVNA titers high enough to be considered responders. We found the TMC+RABORAL V-RG results more promising; after one vaccination with a TMC+RABORAL V-RG mixture, 11 of 12 raccoons had detectable rVNA.
Although not significantly higher than the number of raccoons vaccinated with RABORAL V-RG alone, animals receiving the TMC+RABORAL V-RG vaccine received only half the vaccine dose $\left(10^{7.4}\right.$ $\mathrm{TCID}_{50}$ ) recommended by the manufacturer. Similar to RABORAL V-RG alone, a booster vaccination with the TMC+ RABORAL V-RG mixture led to a $100 \%$ success rate.

While these results should be interpreted cautiously due to our small sample size, our findings offer improvements to the limitations of RABORAL V-RG, especially in relation to species that are currently difficult to vaccinate with the current vaccine formulation, and may offer benefits for enhancing the immunogenicity through the adjustment of physical properties of the vaccine. Improvements in the efficiency of vaccine delivery and immunogenicity of RABORAL V-RG is crucial because obtaining a threshold effect for herd immunity is necessary to curtail the spread of rabies in wildlife reservoirs. The addition of TMC to RABORAL V-RG did not decrease the immunogenicity of the vaccine; however, we did not investigate how the new formulation affected vaccine delivery, including uptake by raccoons handling the vaccine sachet. Our conclusions show potential for the next level of investigation to evaluate how raccoons handle the more viscous vaccine and if those changes affect the number of raccoons successfully vaccinated by new formulations of RABORAL V-RG. Future research will involve allowing raccoons to consume the vaccine, increasing the sample size, and decreasing the titer of 
RABORAL V-RG to determine if TMC is acting as an adjuvant.

Our thanks go to T. Atwood, S. Shriner, R. McLean, M. Dunbar, R. Pleszewski, D. Fitzpatrick, S. Johnson, G. Gathright, and the animal care staff at the National Wildlife Research Center. We thank the Centers for Disease Control Rabies Laboratory for conducting RFFITs. Our research was funded by US Department of Agriculture, Animal and Plant Health Inspection Service, Wildlife Services and as part of a Cooperative Research and Development Agreement with Merial, Ltd. Our mention of commercial products and laboratories herein is for identification purposes only and does not constitute endorsement or censure by US Department of Agriculture, Animal and Plant Health Inspection Service, Wildlife Services.

\section{LITERATURE CITED}

Baudner, B. C., J. C. Verhoef, H. E. Junginger, and G. Del Giudice. 2004. Mucosal adjuvants and delivery systems for oral and nasal vaccination. Drugs of the Future 29: 721-732

Brown, L. J., R. C. Rosatte, C. Fehlner-Gardiner, M. K. Knowles, P. Bachman, J. C. Davis, A Wandeler, K. Sobey, and D. Donovan. 2011. Immunogenicity and efficacy of two rabies vaccines in wild-caught, captive raccoons. Journal of Wildlife Diseases 47: 182-194

Deresienski, D. T., and C. E. Rupprecht. 1989. Yohimbine reversal of ketamine-xylazine immobilization of raccoons (Procyon lotor). Journal of Wildlife Diseases 25: 169-174.

Dodane, V., M. Amin Kahn, and J. R. Merwin. 1999. Effect of chitosan on epithelial permeability and structure. International Journal of Pharmaceutics 182: 21-32.

Eisinger, D., AND H. H. Thulke. 2008. Spatial pattern formation facilitates eradication of infectious disease. Journal of Applied Ecology 45: 415-423.
Fearneyhough, M. G., P. J. Wilson, K. A. Clark, D. R. Smith, D. H. Johnston, B. N. Hicks, and G. M. Moore. 1998. Results of an oral rabies vaccination program for coyotes. Journal of the American Veterinary Medical Association 212: 498-502.

Kotze, A. F., H. L. LueBen, B. J. De Leeuw, A. De Boer, J. C. Verhoef, and H. E. Junginger. 1997. N-trimethyl chitosan chloride as a potential absorption enhancer across mucosal surfaces: In vitro evaluation in intestinal epithelial cells (Caco-2). Pharmaceutical Research 14: 1197 1202.

LueBen, H. L., B. J. De Leeuw, and M. W. E. LANGEMEYer. 1996. Mucoadhesive polymers in peroral peptide drug delivery. VI. Carbomer and chitosan improve the intestinal absorption of the peptide drug buserelin. Pharmaceutical Research 13: 1668-1672.

Sidwa, T. J., P. J. Wilson, G. M. Moore, E. H. Oertli, B. N. Hicks, R. E. Rohde, and D. H. Johnston. 2005. Evaluation of oral rabies vaccination programs for control of rabies epizootics in coyotes and gray foxes: 1995-2003. Journal of the American Veterinary Medical Association 227: 785-792.

Slate, D., T. P. Algeo, K. M. Nelson, R. B. Chipman, D. Donovan, J. D. Blanton, M. Niezgoda, and C. E. Rupprecht. 2009. Oral rabies vaccination in North America: Opportunities, complexities, and challenges. PLoS Neglected Tropical Diseases 3: e529.

Smith, J. S., P. A. Yager, and G. M. Baer. 1996. A rapid fluorescent focus inhibition test (RFFIT) for determining rabies virus-neutralizing antibody. In Laboratory techniques in rabies, 4th Edition, F. X. Meslin, M. M. Kaplan and H. Koprowski (eds.). World Health Organization, Geneva, Switzerland, pp. 181-192.

van der Lubben, I. M., J. C. Verhoef, G. Borchard, and H. E. Junginger. 2001. Chitosan and its derivatives in mucosal drugs and vaccine delivery. European Journal of Pharmaceutical Sciences 14: 201-207.

Submitted for publication 22 November 2011. Accepted 30 March 2012. 